\title{
Internet-Based Treatments - Experiences from Sweden
}

\author{
An Interview with Gerhard Andersson
}

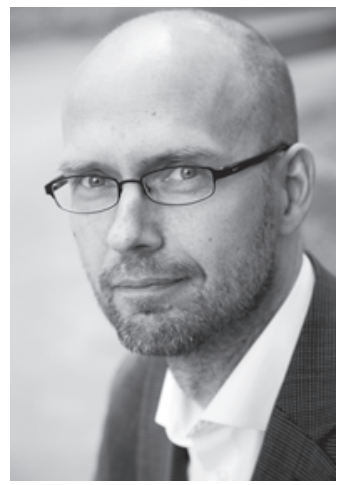

Worldwide, Gerhard Andersson is one of the most influential researchers working on internet-based psychological treatments. Moreover, he is also one of the leading researchers in the field of psychologically oriented tinnitus research. He is full professor of clinical psychology at Linköping University and affiliated professor at the Karolinska Institute in Stockholm at the Department of Clinical Neuroscience, Section Psychiatry. Professor Andersson has been highly productive, having produced more the 300 scientific papers. During his whole career he has worked part-time with patients. Apart from his own research and clinical work, Professor Andersson has editorial responsibilities for several journals including Cognitive Behaviour Therapy, Plos One, BMC Psychiatry, and Scandinavian Journal of Psychology. The interview was conducted by Professor Thomas Berger.

Professor Andersson, you and your team have conducted probably the highest number of studies worldwide on internetbased treatments. How did it all begin?

I have a background as clinical health psychologist and 2 students approached me for supervision on their Master of Science thesis. They had the idea that they wanted to use the internet to treat headache, and we agreed upon a design and conducted one of the first controlled trials in the world on internet-delivered cognitive behaviour therapy (CBT) [Ström et al., 2000]. Then came more Master and PhD students and we also received research funding. As I was working as clinician at the audiology department in Uppsala, Sweden, we fairly rapidly began providing internet treatment for individuals with severe tinnitus. That was already in 1999 [Andersson and Kaldo-Sandström, 2003], making the Audiology Department in Uppsala one of the first clinics in the world to provide internet treatment [Kaldo et al., 2013]. It still does!

\section{Is there a typical Swedish internet-based approach?}

I cannot say we are alone in what we do. More or less simultanously, other groups in the world began doing internet treatment and mainly relied on self-help texts and support from a therapist, e.g., in Australia [Klein and Richards, 2001]. But of course we could say that the typical Swedish approach is characterised by involving therapist support and mainly text-based treatment, which does not require much programming to develop [Andersson et al., 2008]. While we were early to develop new internet treatments, it is often the case that the results we find are replicated in other countries, e.g., the work on social anxiety disorder [Berger et al., 2009].

To what extent are internet-based treatments implemented into regular healthcare in Sweden?

When it comes to tinnitus the treatment has been implemented in 1 specialist setting and the same is the case for anxiety and depression within the Internet Psychiatry Unit at Karolinska Institute, Stockholm. In addition to those 2 places the situation is more scattered with local projects all over Sweden. There are also companies who provide treatment, but I cannot give any figures on how many patients actually get access to internet treatment in Sweden.

\begin{tabular}{ll}
\hline KARGER & @ 2013 S. Karger GmbH, Freiburg \\
Fax +497614520714 & Accessible online at: \\
Information@Karger.com & www.karger.com/ver \\
www.karger.com &
\end{tabular}


There are countries such as Sweden, the Netherlands, Great Britain and Australia in which much research on internetbased treatments is carried out, and in which internet-based treatments are at least partly implemented into the regular healthcare system. In German-speaking countries, most of the larger-scale initiatives on internet-based treatments have just recently started. What are important factors that led to the faster dissemination of internet-based treatments in countries such as Sweden? And what are potential barriers for the dissemination and implementation of internet-based treatments?

First, I think it has to do with local research activities. But there are also important differences between countries. In Sweden the dissemination was rapid in the beginning but since then things have been slower. One reason is technical, as we have tax-funded healthcare but different IT systems in different regions. In Australia there are more active research groups and also in the Netherlands, but in these 2 places there has been a stronger push towards open access programs and prevention [Riper et al., 2008; Calear et al., 2009]. There are many potential barriers and one important hurdle is that internet treatment needs to be integrated in regular psychotherapy services. Here I think groundbreaking work has been done in Germany with Hans Kordy's research group providing internet-based aftercare [Bauer et al., 2011].

As shown in the various contributions of this special issue, it is now established that especially therapist-guided internetbased treatments work for a range of clinical conditions. Less is known regarding predictors of outcome. In your research, but also in your clinical experience, for whom do internet-based treatments work? Are there contraindications for this novel treatment format?

I really wish I had good answers here. One problem is that we tend to rely on the psychotherapy literature when we search for predictors, but it might not be the only place to look. E.g., we and researchers in Germany have studied the role of therapeutic alliance [Knaevelsrud and Maercker, 2006; Preschl et al., 2011; Andersson et al., 2012b], but there may be other aspects such as knowledge acquisition and indeed observations [Berger et al., 2011] making it important in some cases to monitor online activity in an early stage of treatment. We recently found that ratings of satisfaction with treatment modules were predictive of outcome, but again there are very few robust predictors. In general, I think we need to face the fact that not all people prefer or even want to engage in psychological treatment regardless of format.

Internet-delivered treatments are mostly CBT-based. Are other approaches also suitable for internet delivery?

There are now more options. We have found that psychodynamic internet treatment works for depression and anx- iety, the latter being treated with affect phobia treatment [Johansson et al., 2013], and we also should acknowledge that there are different forms of CBT. E.g., we have conducted studies via internet on acceptance and commitment therapy (ACT) for pain, tinnitus and depression [Buhrman et al., 2013]. Somehow disappointing was that attention bias modification for social anxiety disorder did not work as well as we had hoped [Carlbring et al., 2012], and other researchers found the same [Boettcher et al., 2012]. This is also a bit controversial in the CBT field overall, but of course we hoped that it would work as well as it had done in some laboratory studies [Amir et al., 2009].

What about patient preferences? Given a choice, how many patients favour the internet-based approach over, e.g., traditional face-to-face therapy? What is your experience with patients' attitudes towards the internet-based approach?

This is probably something that has to do with how much positive publicity there has been. In Sweden we have had a lot of press, and in general people have heard about this and do not regard it as strange. It is less well known in the USA. Moreover, I think it depends on the condition treated. In one of our more recent comparative trials on social anxiety disorder, we found that patients preferred internet treatment over group treatment [Hedman et al., 2011], but back in 2005 we found the opposite in a study on panic disorder [Carlbring et al., 2005]. To the best of my knowledge there is no study in which this has been tested. We let the patients decide what format they want. Another observation is that patients tend to change their preferences, i.e. the patient appreciates the treatment he has been assigned to when he finds that it helps.

What about therapists' attitudes toward the internet-based approach? In Switzerland some experienced therapists compared their work in a therapist-guided self-help treatment to the assembly line work in a factory. That is nothing therapists want to do after years of study and training to become a qualified psychotherapist. What is your experience with therapists in Sweden? And what do you think will be the role of therapists in the future?

I fully understand this. Indeed I am trained as a CBT therapist myself and would not like to do all treatment over the internet. But here it is probably the case that attitudes change with experience. E.g., therapists notice that they can form a therapeutic alliance online and that patients reveal important information. But I think we eventually need to consider blended treatments where we see our patients in clinic but also treat them and communicate with them via internet. We have just tested whether behavioural activation treatment for depression can work using a smartphone app and 4 live sessions. When we compared this shorter, less time consuming treatment (from the therapist' point of view; for the patients it 
is the same effort), we found that it was just as effective as face-to-face behavioural activation for 10 sessions (Ly et al., unpublished data).

I think it is good to do different things as a therapist and I know that other formats such as group treatment, telephone treatment and use of a book (bibliotherapy) are not applied enough [den Boer et al., 2004]. Finally, the reward for a therapist is when the patient gets better. We see this time after time following internet-based treatment. Another thing is that there are not enough therapists, and if we had cost-effective and acceptable alternatives we probably could treat more patients [Hedman et al., 2012]. There will always be clients who for various reasons should see a therapist in real life and not over the internet.

The content of internet-based treatments is usually based on existing treatment manuals adapted for the internet. One could say that no new approach has been developed with the evolution of this novel treatment format. Would you agree with this and what can traditional psychotherapy and psychotherapy research learn from research on internet-based treatments?

I do not agree. One thing is that we get information on treatment efficacy more rapidly as internet studies tend to be faster to conduct. There are also examples of new treatments like treatment for irritable bowel syndrome, which did not exist before [Ljótsson et al., 2010]. I also think knowledge acquisition has been widely neglected in CBT literature, in spite of the fact that so much of CBT consists of education! We did find that confidence in knowledge increased following treatment of social anxiety disorder [Andersson et al., 2012a]. I was surprised to see that so few studies existed on what patients actually learn in CBT. Moreover, it is strange that text material is not used more often in treatment. We know that patients tend to forget what clinicians say and one advantage with our text-based treatments (and indeed the film clips as well) is that the patient can repeat and work with the material gradually. Another aspect is to get rapid feedback on homework, which I think works better with internet treatment. But it is true that a large part of the content (e.g., exposure instructions) is derived from existing treatment manuals.

More and more practitioners start to include internet-based interventions in their daily practice (e.g., they deliver some interventions via e-mail). There is not much research on this nat- urally evolving development. What do you think about this way of integrating internet-based interventions into practice? Do you have recommendations for practitioners on how to integrate internet-based interventions in their daily work?

I think there is a need for research here. As I said earlier, therapists would probably benefit from using different treatment channels, including the way to communicate. The main issue is of course data security. In some places in the world it is not even allowed to communicate with patients via internet. But I think the development is driven by patient expectations.

What are important open questions in this field that should be addressed in the near future?

In my opinion it is blended treatments (internet and faceto-face). Of course we can and will continue developing internet treatments for different conditions and groups. There are not many studies on, e.g., older people and adolescents. There are also few studies on children [Spence et al., 2006]. I am somewhat hesitant to say that the future lies in novel technology, but of course things will happen there. We have started to conduct trials in smartphone-delivered treatments and so did other research groups [Watts et al., 2013]. But the new technology needs to add something and should not only be a new window for browsing the web.

How do you see the future of internet-based treatments? Should or will they partly replace traditional treatment formats? How should they best complement traditional approaches such as face-to-face therapy?

I think we will get used to the internet to an extent that it will be strange not to have some elements online in just any treatment. We also need to acknowledge that there are many languages, and even if you communicate with a patient in one language, e.g., German, he or she might benefit from information and psychoeducation in another language (e.g., Turkish). Another final issue is to integrate internet services with other forms of healthcare. Medication monitoring, appointment scheduling and other aspects of treatment could very well benefit from modern information technology.

Professor Andersson, thank you very much for this interview.

\section{References}

Amir N, Beard C, Taylor CT, Klumpp H, Elias J, Burns M, Chen X: Attention training in individuals with generalized social phobia: a randomized controlled trial. J Consult Clin Psychol 2009;77:961973.
Andersson G, Bergström J, Buhrman M, Carlbring P, Holländare F, Kaldo V, Nilsson-Ihrfelt E, Paxling B, Ström L, Waara J: Development of a new approach to guided self-help via the internet. The swedish experience. J Technol Human Serv 2008; 26:161-181.
Andersson G, Carlbring P, Furmark T, on behalf of the SOFIE Research Group: Therapist experience and knowledge acquisition in internet-delivered CBT for social anxiety disorder: a randomized controlled trial. PloS One 2012a;7:e37411. 
Andersson G, Kaldo-Sandström V: Treating tinnitus via the internet. CME Journal Otorhinolaryngology, Head and Neck Surgery 2003;7:38-40.

-Andersson G, Paxling B, Wiwe M, Vernmark K Bertholds Felix C, Lundborg L, Furmark T, Cuijpers $\mathrm{P}$, Carlbring P: Therapeutic alliance in guided internet-delivered cognitive behavioral treatment of depression, generalized anxiety disorder and social anxiety disorder. Behav Res Ther 2012b;50: 544-550.

Bauer S, Wolf M, Haug S, Kordy H: The effectiveness of internet chat groups in relapse prevention after inpatient psychotherapy. Psychother Res 2011;21: 219-226.

- Berger T, Caspar F, Richardson R, Kneubühler B, Sutter D, Andersson G: Internet-based treatmen of social phobia: a randomized controlled tria comparing unguided with two types of guided selfhelp. Behav Res Ther 2011;48:158-169.

- Berger T, Hohl E, Caspar F: Internet-based treatment for social phobia: a randomized controlled trial. J Clin Psychol 2009;65:1021-1035.

Boettcher J, Berger T, Renneberg B: Internet-based attention training for social anxiety: a randomized controlled trial. Cognitive Ther Res 2012;36:552536.

Buhrman M, Skoglund A, Husell J, Bergström K, Gordh T, Hursti T, Bendelin N, Furmark T, Andersson G: Guided internet-delivered acceptance and commitment therapy for chronic pain patients: a randomized controlled trial. Behav Res Ther 2013;51:307-315.

Calear AL, Christensen H, Mackinnon A, Griffith KM, O'Kearney R: The youthmood project: a cluster randomized controlled trial of an online cognitive behavioral program with adolescents. J Consult Clin Psychol 2009;77:1021-1032.
Carlbring P, Apelstrand M, Sehlin H, Amir N, Rousseau A, Hofmann S, Andersson G: Internet-delivered attention training in individuals with social anxiety disorder - a double blind randomized controlled trial. BMC Psychiatry 2012;12:66.

Carlbring P, Nilsson-Ihrfelt E, Waara J, Kollenstam C, Buhrman M, Kaldo V, Söderberg M, Ekselius L, Andersson G: Treatment of panic disorder: live therapy vs. self-help via internet. Behav Res Ther 2005;43:1321-1333.

den Boer PC, Wiersma D, Van den Bosch RJ: Why is self-help neglected in the treatment of emotional disorders? A meta-analysis. Psychol Med 2004;34: 959-971.

Hedman E, Andersson G, Ljótsson B, Andersson E, Rück C, Mörtberg E, Lindefors N: Internet-based cognitive behavior therapy vs. cognitive behavioral group therapy for social anxiety disorder: a randomized controlled non-inferiority trial. PloS One 2011;6:e18001.

Hedman E, Ljotsson B, Lindefors N: Cognitive behavior therapy via the internet: a systematic review of applications, clinical efficacy and cost-effectiveness. Expert Rev Pharmacoecon Outcomes Res 2012;12:745-764.

Johansson R, Björklund M, Hornborg C, Karlsson S, Hesser H, Ljótsson B, Rousseau A, Frederick RJ, Andersson G: Affect-focused psychodynamic psychotherapy for depression and anxiety through the internet: a randomized controlled trial. PeerJ 2013;1:e102

Kaldo V, Haak T, Buhrman M, Alfonsson S, Larsen H-C, Andersson G: Internet-based cognitive behaviour therapy for tinnitus patients delivered in a regular clinical setting - outcome and analysis of treatment drop-out. Cogn Behav Ther 2013;42:146-158.
Klein B, Richards JC: A brief internet-based treatment for panic disorder. Behav Cogn Psychoth 2001;29:113-117.

Knaevelsrud C, Maercker A: Does the quality of the working alliance predict treatment outcome in online psychotherapy for traumatized patients? J Med Internet Res 2006;8:e31.

Ljótsson B, Falk L, Wibron Vesterlund A, Hedman E, Lindfors P-J, Rück C, Hursti T, Andréewitcha S, Jansson L, Lindefors N, Andersson G: Internetdelivered exposure and mindfulness based therapy for irritable bowel syndrome - a randomized controlled trial. Behav Res Ther 2010;48:531-539.

- Preschl B, Maercker A, Wagner B: The working alliance in a randomized controlled trial comparing online with face-to-face cognitive-behavioral therapy for depression. BMC Psychiatry 2011;11:189.

Riper H, Kramer J, Smit F, Conijn B, Schippers G Cuijpers P: Web-based self-help for problem drinkers: a pragmatic randomized trial. Addiction 2008; 103:218-227.

Spence SH, Holmes JM, March S, Lipp OV: The feasibility and outcome of clinic plus internet delivery of cognitive-behavior therapy for childhood anxiety. J Consult Clin Psychol 2006;74:614-621.

Ström L, Pettersson R, Andersson G: A controlled trial of self-help treatment of recurrent headache conducted via the internet. J Consult Clin Psychol 2000;68:722-727.

Watts S, Mackenzie A, Thomas C, Griskaitis A, Mewton L, Williams A, Andrews G: CBT for depression: a pilot RCT comparing mobile phone vs. computer. BMC Psychiatry 2013;13:49. 